\title{
Immunopathology of the skin
}

By E. H. Beutner, T. P. Chorzelski, and S. F. Bean. 1979, 2nd ed. New York: John Wiley and Sons. Pp. xxii and 497. £23.80.

Since the initial description of autoantibody of pemphigus by Beutner and Jordan in 1964, immunofluorescent-labelled antibody techniques have become increasingly popular for the diagnosis and investigation of skin diseases. Apart from the editors, 44 distinguished authors from nine countries have contributed to this book on the principles and practice of immunofluorescence techniques.

The first chapter describes clearly the indications for direct and indirect immunofluorecence and grades the information obtained as diagnostic (as in pemphigus, pemphigoid and dermatitis herpetiformis), characteristic (lupus erythematosus and its variants) or merely interesting (vasculitis and psoriasis). This is followed by two very useful chapters on methods, with particular emphasis on those aspects of technique that determine reliability of results. Most of the book is devoted to detailed reviews of the immunofluorescence findings and their interpretation in various diseases. Where there is controversy, e.g., in the case of "mixed connective tissue disease", linear IgA deposits in dermatitis herpetiformis-like diseases of children and adults and the stratum-corneum antibody in psoriasis, the different views are presented, usually in adjacent chapters. The book is largely devoted to the use of immunofluorescence, but there is a most useful review on enzyme-antibody methods, particularly with immunoperoxidase.

Although the book is titled Immunopathology of the skin, those disorders that cannot be investigated readily by labelled-antibody techniques are discussed either cursorily or not at all. To this extent the title is misleading, in that the immunofluorescence findings are not interpreted in a broader immunological context. The only chapter that attempts to do this is on the "Nature of autoimmunity" but, unfortunately, this is one of the least readable contributions; it might have been easier to follow if it had been placed at the end of the book.

There can be no doubt that this is a most useful, if expensive, compendium of practical information on labelled-antibody techniques in dermatology, providing an up-to-date review of the literature.

\section{KeNNEDY}

\section{The molecular biology of picornaviruses}

Edited by R. Perez-Bercoff. 1979. (NATO Advanced Study Institute Series). New York and London: Plenum Press. Pl. xiv and 371. US\$39.50.

This book is based on the proceedings of a meeting held in Maratea in Italy in September 1978 and consists of 17 chapters of variable quality and interest. As one would expect, most of the information presented is already available elsewhere; nevertheless there is certainly a justification for books of this nature in that it allows contributors to present their speculations in a rational way and also provides an invaluable source of information for those wishing to be brought up to date (i.e., to 1978) with current research.

One distinct disadvantage of organising and publishing the proceedings of a meeting on such a relatively restricted topic is that there will inevitably be overlaps of interest which will, in turn, lead to a degree of reiteration with somewhat soporific consequences. This is reflected in the book, in which subjects recur with regularity in two, three or even four chapters. Thus, the processing of polyprotein, the significance of poly $\mathrm{C}$ tracts and the mechanism of cellular polypeptide inhibition, amongst others, receive repeated attention. The organiser of the meeting was obviously well aware of this defect and had prudently persuaded a number of eminent researchers in related fields to make a contribution and this is no doubt added some perspective to the meeting and has certainly improved the quality of the book.

The initial chapter by Scraba provides a very useful summary of the current state of play of research on the structural aspects of picornaviruses, particularly with respect to the protein 
components. An able presentation by Fellner on virus RNA genomes, outlining the latest results of sequencing studies, is timely in view of the current upsurge of interest in the development of these techniques and in their application to comparative investigations. Structure-function relationships are discussed by Brown and the chapter reflects the relative paucity of knowledge of the functional aspects of the virus and cell interactions. This comment is applicable to most other areas of animal virology and is a reflection of our inability to investigate multicomponent systems in any meaningful way with the techniques and information currently available. Indeed, the medical microbiologist will not find very much in this book of immediate application. Nevertheless, on careful reading it will be evident that progress, particularly over the last 10 years, in our general understanding of molecular events has been considerable, and in some areas application of these discoveries to disease problems will certainly become much more apparent in the future. Several chapters examine various aspects of virus polypeptide synthesis and processing, the most outstanding being that by Korant, who discusses in some detail the current state of knowledge with respect to cellular and viral proteases in these viruses. Remarkably little is known of the enzymes involved in the processing of viral polypeptides although they seem to play a key role in the maturation of a wide variety of viruses. One of the more exciting recent findings in picornaviruses is that they, like some DNA-containing viruses, possess a protein apparently covalently linked to the $5^{\prime}$ terminus of their genomes. The discovery of this protein, its properties and its possible function during infection are expertly described by Wimmer and provides one of the most interesting chapters in this volume. A review by Jackson of mammalian protein synthesis gives an excellent background for consideration of the problems associated with the control of virus polypeptide synthesis- - these are discussed in some of the later chapters. Aspects of interferon research are reviewed at some length in three chapters and the more recent observations on the significance of protein kinases and endonucleases and the role of $2^{\prime} 5^{\prime}$ oligo $\mathrm{A}$ in the action of interferon are very adequately covered and broaden the perspectives of the book significantly.

In summary, this book is not one that need be within immediate reach but will be a very useful addition to the library for those who wish to keep abreast of current developments.

W. C. Russell

\section{The interferon system}

By W. E. Stewart II. 1979. Vienna and New York: Springer Verlag. Pp. xii and 421. US\$53.90.

Interferons are proteins that have an astonishingly high intrinsic activity, and that currently are proving of great interest to workers in fields as diverse as clinical medicine, molecular biology and protein chemistry, to name but a few. It is thus no light task for one person to write an advanced text book dealing with these substances. Dr Stewart must be congratulated on not only undertaking this herculean task but also on completing it so successfully.

He has, himself, contributed much to several areas of interferon research. Correspondingly, the sections in this book on, for example, the structure, characterisation and heterogeneity of interferons, contain excellent reviews of the state of the art up to the end of 1978. Inevitably, there are other areas, for example interferon and clinical medicine, where Dr Stewart writes without personal experience, and here the treatment is correspondingly shorter and the conclusions are less decisive.

The index, not prepared by Dr Stewart himself, is a disappointment, with inaccuracies, e.g., Renoviruses instead of Arenoviruses and some major errors and omissions, e.g., the main section on species specificity is not indexed. On the other hand, there is an enormous and useful bibliography.

All in all, this is a tour de force. Dr Stewart has produced a book that all those working on interferon will want to own. It can be thoroughly recommended to others as a valuable reference source. 